\title{
Two-year clinical outcomes after implantation of an everolimus-eluting bioresorbable scaffold (Absorb) in stable angina and acute coronary syndrome patients. Single-centre real-life registry data
}

\author{
leva Briede ${ }^{1}$, Inga Narbute ${ }^{2}$, Indulis Kumsars ${ }^{1}$, Dace Sondore ${ }^{2}$, Karlis Trushinskis², Sanda Jegere ${ }^{2}$, \\ Gustavs Latkovskis ${ }^{1}$, Karlis Strenge ${ }^{2}$, Ainars Rudzitis ${ }^{2}$, Andrejs Erglis ${ }^{1}$ \\ ${ }^{1}$ Latvian Centre of Cardiology, Pauls Stradins Clinical University Hospital, University of Latvia, Riga, Latvia \\ ${ }^{2}$ Latvian Centre of Cardiology, Pauls Stradins Clinical University Hospital, Riga, Latvia
}

Adv Interv Cardiol 2018; 14, 2 (52): 144-148

DOI: https://doi.org/10.5114/aic.2018.76405

\begin{abstract}
A bstract
Aim: The aim of this long-term registry data was to evaluate 2-year clinical and angiographic outcomes after implantation of everolimus-eluting bioresorbable scaffolds (Absorb) from the Latvian Centre of Cardiology Real-life Registry.

Material and methods: Between November 2012 and December 2014 in the Centre of Cardiology Real-life Bioresorbable Vascular Scaffold Registry, 187 patients with stable angina or acute coronary syndrome and available 2-year follow-up were selected. All patients had percutaneous coronary intervention (PCI) following bioresorbable scaffold (Absorb) implantation. At 2 years, clinical parameters were analysed in stable angina and acute coronary syndrome subgroups: all-cause death, cardiac death, non-cardiac death, myocardial infarction (MI), target lesion revascularization (TLR), target vessel revascularization (TVR), scaffold thrombosis (ST), cerebral infarction, in-scaffold restenosis and bleeding.

Results: The clinical follow-up rate at 2 years was 96.2\%. In-hospital death occurred in $2(1.1 \%)$ patients, and $1(0.5 \%)$ patient had in-hospital MI. At 2 years, the rate of all-cause death was 3.9\% $(n=7)$, MI 1.6\% $(n=3)$, TLR 3.9\% $(n=7)$, and TVR $8.4 \%(n=15)$. Between hospital discharge and 2-year follow-up scaffold thrombosis occurred in 2 (1.1\%) patients. In-hospital scaffold thrombosis occurred in $1(0.5 \%)$ patient due to clopidogrel resistance, and 1 additional case of scaffold thrombosis occurred at 5 days after implantation (0.5\%).

Conclusions: Bioresorbable scaffolds showed acceptable efficacy (target lesion revascularization) and safety (cardiac death, myocardial infarction, and scaffold thrombosis) results at mid-term follow-up in stable angina and acute coronary syndrome patients.
\end{abstract}

Key words: percutaneous coronary intervention, bioresorbable vascular scaffold, scaffold thrombosis.

\section{Introduction}

In recent years, second-generation drug-eluting stents (DES) have demonstrated improved efficacy and safety over first-generation DES. Nonetheless, even current generation DES are limited by late adverse events, including stent thrombosis and restenosis [1, 2]. Bioresorbable vascular scaffolds (BVS) are transient devices that, like metallic stents, prevent acute closure of coronary vessels and with the eluting drug eliminate neointimal proliferation. Permanent implantation of metal and polymers in the vessel wall can provoke inflammation, endothelial dysfunction, ongoing tissue growth within the stent frame, and neoatherosclerosis. To reduce these late clinical consequences, fully bioresorbable scaffolds that also elute antiproliferative drugs were developed [3]. The first generation BVS Absorb (Abbott Vascular, Abbott Park, Illinois) showed acceptable results in the first clinical testing [4]. The latest publications have drawn attention to the possible increase in scaffold thrombosis with BVS compared to the gold standard DES $[5,6]$. Some registries showed safe and successful BVS implantation in the acute coronary syndrome patient population [7]. Scaffold thrombosis was associated with lesion selection and implantation technique failure. In our registry

\section{Corresponding author:}

leva Briede MD, Latvian Centre of Cardiology, Pauls Stradins Clinical University Hospital, University of Latvia, 13 Pilsonu St, LV-1002 Riga, Latvia, phone: +371 26400575, e-mail: ieva.briede@gmail.com

Received: 5.01.2018, accepted: 5.03.2018. 
we wanted to collect real-life data from our single centre and analyse patients' outcomes after BVS implantation at mid-term follow-up.

\section{Aim}

The aim of this long-term registry analysis was to evaluate 2-year clinical and angiographic outcomes after implantation of everolimus-eluting bioresorbable scaffolds (Absorb) from the Centre of Cardiology Real-life Registry.

\section{Material and methods}

Between November 2012 and December 2014 in the Centre of Cardiology, 250 patients with documented stable angina and/or acute coronary syndrome received a BVS and were included in the registry. The coronary vessel reference diameter by visual estimate had to be $\leq 4.0 \mathrm{~mm}$ and $\geq 2.5 \mathrm{~mm}$ to be eligible for BVS implantation. Of the 450 patients who were included in the registry between November 2012 and January 2017, 250 patients were included in the registry between 2012 and 2014. From them, 50 patients have left main bifurcation treatment and were excluded from the data analysis. Finally 187 patients were selected for data analysis because these patients reached 2-year clinical follow-up. Dual antiplatelet therapy (DAPT) was prescribed at least for 12 months for all patients. At 2 years, patients received a phone call follow-up visit. Seven patients were lost to follow-up. Angiographic follow-up was available in $46.0 \%(82 / 178)$ of patients. Angiographic follow-up mostly was available due to staged treatment of another coronary lesion or if the patient had angina symptoms with a positive treadmill stress test. All clinical and angiographic data at baseline and at follow-up were collected in one database. Main endpoints of the database analysis included rates of major adverse cardiac events (MACE): all-cause death, myocardial infarction, cerebral infarction, coronary artery bypass (CABG), major bleeding, scaffold thrombosis, in-scaffold restenosis, target lesion revascularization (TLR), target vessel revascularization (TVR). Scaffold thrombosis was categorized as acute if $<1$ day, sub-acute if 1-30 days and late if $>30$ days [8].

\section{Statistical analysis}

Statistical analyses were performed using SPSS version 24.0 software (IBM SPSS, Corp., Armonk, NY). Continuous variables were expressed as mean and standard deviation (SD).

\section{Results}

From all patients included between November 2012 and December 2014 in the Centre of Cardiology Real-life Registry, 187 patients with stable angina and acute coronary syndrome and 2-year follow-up were selected.
Coronary lesion types were $A, B$ and $C$ according to the ACC/AHA classification. Main coronary lesion types were $A$ and $B$ [9].

\section{Patient demographics}

Baseline clinical characteristics for all patients are shown in Table I. Mean patient age was $56.74 \pm 11.85$ years. Male gender was $78.6 \%$. The majority of patients, $79.1 \%$, presented with stable angina. In the acute coronary syndrome patient group, ST-segment elevation myocardial infarction (STEMI) represented $9.6 \%$ of patients, non-STEMI 3.2\% and unstable angina $5.9 \%$. $41.2 \%$ of patients had documented previous percutanous coronary intervention $(\mathrm{PCl})$ with stent implantation.

\section{Lesion characteristics and procedural details}

Lesion characteristics and procedural details are shown in Table II. Multi-vessel disease was noted in $61.5 \%$ of patients and true bifurcation lesions in $14.9 \%$. Bioresorbable vascular scaffolds implantation in $49.7 \%$ was performed in the left anterior descending (LAD) coronary artery, $25.1 \%$ in the right coronary artery (RCA) and $14.4 \%$ in the left circumflex (LCX) artery. Lesions were mostly localized proximally and in the middle segment of the artery, $65.8 \%$ and $60.4 \%$ respectively. Procedural characteristics are shown in Table III. Pre-dilatation was

Table I. Clinical characteristics of registry population $(n=187)$

\begin{tabular}{|c|c|}
\hline Clinical characteristics & $N(\%)$ or mean \pm SD \\
\hline \multicolumn{2}{|l|}{ Gender: } \\
\hline Female & $40(21.4)$ \\
\hline Male & $147(78.6)$ \\
\hline Age [years] & $56.74 \pm 11.85$ \\
\hline Arterial hypertension & $151(80.7)$ \\
\hline Dyslipidemia & $129(69.0)$ \\
\hline Diabetes mellitus & $33(17.6)$ \\
\hline Smoking & $29(15.5)$ \\
\hline STEMI & $18(9.6)$ \\
\hline NSTEMI & $6(3.2)$ \\
\hline Unstable angina & $11(5.9)$ \\
\hline Stable angina & $148(79.1)$ \\
\hline Silent ischemia & $4(2.1)$ \\
\hline Previous myocardial infarction & $65(34.8)$ \\
\hline Previous PCl & $77(41.2)$ \\
\hline CABG & $5(2.7)$ \\
\hline Previous cerebral infarction & $10(5.3)$ \\
\hline Peripheral artery disease & $8(4.3)$ \\
\hline Chronic kidney disease & $10(5.3)$ \\
\hline
\end{tabular}


Table II. Angiographic data for target lesion localization $(n=187)$

\begin{tabular}{lc}
\hline Angiographic data & $\boldsymbol{N}(\%)$ \\
\hline Multi-vessel disease & $115(61.5)$ \\
\hline Target lesion vessel: & $2(1.1)$ \\
\hline Left main (LM) & $93(49.7)$ \\
\hline Left anterior descending (LAD) & $27(14.4)$ \\
\hline Left circumflex (LCX) & $47(25.1)$ \\
\hline Right coronary artery (RCA) & $6(3.2)$ \\
\hline First diagonal branch (D1) & $7(3.8)$ \\
\hline Marginal branch (OM) & $4(2.1)$ \\
\hline Ramus intermedius (RIM) & $34(18.2)$ \\
\hline Target lesion localization: & $123(65.8)$ \\
\hline Ostial & $113(60.4)$ \\
\hline Proximal & $24(12.8)$ \\
\hline Middle & $28(14.9)$ \\
\hline Distal
\end{tabular}

Table III. Procedural data for angioplasty $(n=187)$

\begin{tabular}{lc} 
Procedural data & $\boldsymbol{N}(\%)$ or mean \pm SD \\
\hline Radial approach & $142(75.9)$ \\
\hline IVUS use & $32(17.1)$ \\
\hline OCT use & $31(16.6)$ \\
\hline GP-Ilb/Illa inhibitors & $112(59.9)$ \\
\hline Pre-dilatation: & $173(92.5)$ \\
\hline Regular balloon & $86(50.3)$ \\
\hline Cutting balloon & $87(49.7)$ \\
\hline Pre-dilatation balloon diameter [mm] & $2.92 \pm 0.48$ \\
\hline Pre-dilatation balloon length [mm] & $15.80 \pm 8.66$ \\
\hline Scaffold length [mm] & $20.10 \pm 6.48$ \\
\hline Scaffold diameter [mm] & $3.17 \pm 0.36$ \\
\hline Post-dilatation & $173(92.5)$ \\
\hline Post-dilatation balloon diameter [mm] & $3.46 \pm 0.41$ \\
\hline Post-dilatation balloon maximal & $17.11 \pm 3.34$ \\
atmospheres
\end{tabular}

done in almost all cases (92.5\%); in $49.7 \%$ a plaque modification technique with a cutting balloon was used, and in $50.3 \%$ pre-dilatation was done with a regular balloon (1: 1 ratio). The mean scaffold length treated was 20.10 $\pm 6.48 \mathrm{~mm}$ and $3.17 \pm 0.36 \mathrm{~mm}$ for the treated mean vessel diameter. Post-dilatation was performed in $92.5 \%$ of cases with mean post-dilatation balloon diameter 3.46 $\pm 0.41 \mathrm{~mm}$ with maximal pressure used $17.11 \pm 3.34 \mathrm{~atm}$.

\section{Clinical outcomes}

Patient clinical and angiographic outcomes are shown in Table IV. Results are shown for all patients and separated by groups for stable angina $(n=187)$ and acute coronary syndrome $(n=29)$. Two patient deaths were recorded during the hospitalization period. One death occurred in the acute coronary syndrome group (3.4\%; 1/29), not association with scaffold thrombosis. The patient died due to progression of acute heart failure during myocardial infarction. The second hospital death was in the stable angina group and was associated with acute scaffold thrombosis. Unfortunately, the scaffold thrombosis occurred due to clopidogrel resistance (vasodilator-stimulated phosphoprotein analyses - VASP); a standardized flow cytometric assay test was positive. From 187 patients, 7 (3.8\%) were lost to follow-up. All other patients (96.2\%) reached 2-year clinical follow-up. All-cause death (cancer, cerebrovascular, unknown) was 3.9\% (7/178). Myocardial infarction during follow-up occurred in $1.6 \%$ (3/178) of patients. Definite sub-acute scaffold thrombosis occurred in 1 patient $(0.5 \% ; 1 / 178), 5$ days after scaffold implantation. The patient presented with STEMI with thrombotic occlusion of the first diagonal branch where a $2.5 \mathrm{~mm} \times 18 \mathrm{~mm}$ BVS had been previously implanted. He was treated with plain old balloon angioplasty (POBA) and scaffold optimization. Twelve-month DAPT was prescribed with aspirin and ticagrelor. After that, the patient reached 2-year follow-up without any other clinical event.

Angiographic in-scaffold restenosis was recorded in $6 \%(5 / 82)$ of patients. Treated in-scaffold restenosis occurred in $4.8 \%$ (4/82) of patients with clinically positive angina symptoms. At 2 years, TLR occurred in 3.9\% (7/178) of patients. Target vessel revascularization was performed in $8.4 \%(15 / 178)$ of patients.

\section{Discussion}

Bioresorbable vascular scaffolds is relatively new in interventional cardiology. First generation BVS in simple de-novo lesions has been proven to be almost as good as DES with comparable MACE event rates (ABSORB, ABSORB II) and in all comer registries as in the retrospective registry GHOST-EU, the target lesion failure rate (TLF) at 1 year was very acceptable given the lesion and patient complexity; however, an increase in early ST was noted $[10,11]$. The ABSORB III trial demonstrated that the scaffold was non-inferior to the Xience stent with respect to target lesion failure at 1 year [12]. Absorb II 3-year BVS outcomes showed that treatment with BVS was associated with a higher scaffold thrombosis (3\%) rate compared with the newest generation DES [5]. Sotomi et al. conducted pre- and post-procedural intravascular ultrasound (IVUS) matching analysis from the Absorb II trial, analysing pre-procedural minimal lumen area (MLA). They concluded that to achieve equivalent acute gain in the 
Table IV. Clinical and angiographic results

\begin{tabular}{|c|c|c|c|}
\hline MACE (clinical and angiographic) & $\begin{array}{l}\text { All patients } \\
(n=187)\end{array}$ & $\begin{array}{l}\text { Stable patients } \\
\quad(n=158)\end{array}$ & $\begin{array}{c}\text { Acute patients } \\
(n=29)\end{array}$ \\
\hline Hospital death ${ }^{1}$ & $1.1(2 / 187)$ & $0.6(1 / 158)$ & $3.4(1 / 29)$ \\
\hline Hospital scaffold thrombosis & $0.5(1 / 157)$ & $0.6(1 / 158)$ & 0 \\
\hline Hospital myocardial infarction & $0.5(1 / 187)$ & $0.6(1 / 158)$ & 0 \\
\hline Lost to follow-up & $3.8(7 / 187)$ & $1.8(3 / 158)$ & $13.7(4 / 29)$ \\
\hline All-cause death: & $3.9(7 / 178)$ & $4.4(7 / 155)$ & 0 \\
\hline Cancer & $1.6(3 / 178)$ & $1.9(3 / 155)$ & 0 \\
\hline Cerebrovascular & $1.1(2 / 178)$ & $1.3(2 / 155)$ & 0 \\
\hline Unknown & $1.1(2 / 178)$ & $1.2(2 / 155)$ & 0 \\
\hline Myocardial infarction ${ }^{1}$ & $1.6(3 / 178)$ & $0.6(1 / 155)$ & $7.1(2 / 25)$ \\
\hline Cerebral infarction & $1.7(3 / 178)$ & $1.9(3 / 155)$ & 0 \\
\hline CABG & 0 & 0 & 0 \\
\hline Major bleeding & $1.1(2 / 178)$ & $1.3(2 / 155)$ & 0 \\
\hline \multicolumn{4}{|l|}{ Post-discharge scaffold thrombosis: } \\
\hline Definite & $0.5(1 / 178)$ & $0.6(1 / 155)$ & 0 \\
\hline Possible & 0 & 0 & 0 \\
\hline Probable & 0 & 0 & 0 \\
\hline Total scaffold thrombosis & $1.1(2 / 180)$ & $1.1(2 / 180)$ & 0 \\
\hline Angiographic follow-up & $46.0(82 / 178)$ & $46.4(72 / 155)$ & $40.0(10 / 25)$ \\
\hline Angiographic in-scaffold restenosis & $6.0(5 / 82)$ & $6.9(5 / 72)$ & 0 \\
\hline \multicolumn{4}{|l|}{ Restenosis type: } \\
\hline Focal & $1.2(1 / 82)$ & $1.1(1 / 72)$ & 0 \\
\hline Diffuse intra-scaffold & $4.8(4 / 82)$ & $5.5(4 / 72)$ & 0 \\
\hline Treated restenosis & $4.8(4 / 82)$ & $5.5(4 / 72)$ & 0 \\
\hline TLR & $3.9(7 / 178)$ & $4.5(7 / 158)$ & 0 \\
\hline$T V R^{*, 2}$ & $8.4(15 / 178)$ & $7.7(12 / 155)$ & $12(3 / 25)$ \\
\hline
\end{tabular}

Data are presented as percentage of total number (\%) and number of patients from total number (n/n-total). * Five planned elective PCI, three metal stent restenosis. ${ }^{1}$ Non-statistically significant difference between groups. ${ }^{2}$ Statistically significant difference for TVR between stable and acute patient groups ( $p<0.03$ ).

Absorb compared to the Xience, implantation of the scaffold may require more aggressive strategies for pre- and post-dilation and implantation than the technique used in the ABSORB II trial [13]. Three-year clinical outcomes of the ABSORB China randomized trial were recently published. They concluded that BVS and Cobalt-Cromium Everolimus-eluting metallic stents (CoCr-EES) had similar results up to 3-year follow-up, at which time the scaffold has completely resorbed. Definite/probable ST $0.9 \%$ vs. $0.0 \%(p=0.50)$ [14].

Our centre's real-life registry of 2-year data shows comparable results with the current gold standard. As described before in the literature, in the "Predilatation-Sizing-Postdilatation (PSP) implantation technique" of BVS, the most important steps are vessel preparation before BVS, appropriate sizing and post-dilatation of the scaffold to optimize the result. Nevertheless, our centre's local recommendations have required that "PSP" be performed for all stent/scaffold interventions for the last few years. For this particular BVS cohort, pre-dilatation and post-dilatation was done in $92.5 \%$, which resulted in good mid-term outcomes. Same local centre recommendations include usage of GPIIb/IIla receptor blockers. In this particular data registry we used GPIIb/IIIa in 59.9\% $(n=112)$ of cases, due to the long procedure time or long target lesion treatments where more than one stent/ scaffold implantation were needed. High rate of the radial approach and cutting balloon predilatation as in our centre's practice requires GPIIb/IIla administration with low bleeding risk and low scaffold thrombosis rates.

The use of imaging techniques such as IVUS and/or optical coherence tomography (OCT) in BVS implantation could be critical to achieve good long-term results. In more complex $\mathrm{PCl}$ cases where BVS is used, our cen- 
tre's strategy is "I-PSP" - Imaging, Pre-treatment, Sizing, Post-dilatation.

Stable angina patients at our centre receive standard DAPT therapy after PCI: aspirin and clopidogrel 6 to 12 months. Our registry experience with one acute scaffold thrombosis due to clopidogrel resistance changed our strategy for stable angina patients to more aggressive and longer DAPT usage, at-least 1-month ticagrelor continuously up to 12-24 months. Nevertheless, in total 450 patients were included in this registry and more precise data will be reported when patients reach more than 2-year follow-up.

A limitation of this real-life registry could be that the cohort did not reach the complete follow-up, yet the follow-up rate was quite high at $96.2 \%$. The imaging techniques IVUS and OCT were used only in $17.1 \%$ and $16.6 \%$ of cases, mostly during complex lesions, but they should be used more. Another limitation is that this is single-centre evaluation with no adjudication of events. As this is a real-life registry, no angiographic follow-up was required, which might have led to biased results regarding TLR.

\section{Conclusions}

Our single-centre, real-life BVS registry data show a relatively low rate of MACE and scaffold thrombosis at mid-term 2-year clinical follow-up in stable angina and acute coronary syndrome patients. These results are comparable with current gold standards and show that BVS implantation could be safe.

\section{Acknowledgments}

This registry was supported in part by the National Research Program "Biomedicine for Public Health" (BIOMEDICINE) and by a grant from the corporation "Sistemu Inovacijas".

\section{Conflict of interest}

One author has received consultancy fees, a research grant to the institution from Abbott Vascular, Boston Scientific, Biosensors, Cordis J\&J, Medtronic. Other authors declare no conflict of interest.

\section{References}

1. Navarese EP, Kowalewski M, Kandzari D, et al. First-generation versus second-generation drug- eluting stents in current clinical practice: updated evidence from a comprehensive meta-analysis of randomised clinical trials comprising 31379 patients. Open Heart 2014; 1: e000064.

2. Palmerini T, Benedetto U, Biondi-Zoccai G, et al. Long-term safety of drug-eluting and bare-metal stents: evidence from a comprehensive network meta-analysis. J Am Coll Cardiol 2015; 65: 2496-507.

3. Otsuka F, Vorpahl M, Nakano M, et al. Pathology of second-generation everolimus-eluting stents versus first-generation siroli- mus- and paclitaxel-eluting stents in humans. Circulation 2014; 129: 211-23.

4. Onuma Y, Serruys PW. Bioresorbable scaffold: the advent of a new era in percutaneous coronary and peripheral revascularization? Circulation 2011; 123: 779-97.

5. Serruys PW, Chevalier B, Sotomi Y, et al. Comparison of an everolimus-eluting bioresorbable scaffold with an everolimus-eluting metallic stent for the treatment of coronary artery stenosis (ABSORB II): a 3 year, randomised, controlled, single-blind, multicentre clinical trial. Lancet 2016; 388: 2479-91.

6. Wykrzykowska JJ, Kraak RP, Hofma SH, et al.; AIDA Investigators. Bioresorbable scaffolds versus metallic stents in routine $\mathrm{PCl}$. N Engl J Med 2017; 376: 2319-28.

7. Rzeszutko $七$, Siudak Z, Tokarek T, et al. Twelve months clinical outcome after bioresorbable vascular scaffold implantation in patients with stable angina and acute coronary syndrome. Data from the Polish National Registry. Adv Interv Cardiol 2016; 12: 108-15.

8. Cutlip DE, Windecker S, Mehran R, et al.; Academic Research Consortium. Clinical end points in coronary stent trials: a case for standardized definitions. Circulation 2007; 115: 2344-51.

9. Ellis SG, Vandormael MG, Cowley MJ, the POSCH Group. Coronary morphologic and clinical determinates of procedural outcome with angioplasty for multivessel coronary disease: implications for patient selection. Circulation 1990; 82: 1193-202.

10. Capodanno D, Gori T, Nef H, et al. Percutaneous coronary intervention with everolimus-eluting bioresorbable vascular scaffolds in routine clinical practice: early and midterm outcomes from the European multicentre GHOST-EU registry. Eurolntervention 2015; 10: 1144-53.

11. Rzeszutko $Ł$, Tokarek T, Siudak Z, et al. Patient profile and periprocedural outcomes of bioresorbable vascular scaffold implantation in comparison with drug-eluting and bare-metal stent implantation. Experience from ORPKI Polish National Registry 2014-2015. Adv Interv Cardiol 2016; 12: 321-8.

12. Baron SJ, Lei Y, Chinnakondepalli K, et al.; the ABSORB III Investigators. Economic outcomes of bioresorbable vascular scaffolds versus everolimus-eluting stents in patients undergoing percutaneous coronary intervention 1-year results from the ABSORB III Trial. JACC Cardiovasc Interv 2017; 10: 774-82.

13. Sotomi Y, Ishibashi Y, Suwannasom P, et al. Acute gain in minimal lumen area following implantation of everolimus-eluting ABSORB biodegradable vascular scaffolds or Xience Metallic Stents: intravascular ultrasound assessment from the ABSORB II trial. JACC Cardiovasc Interv 2016; 9: 1216-27.

14. Xu B, Yang Y, Han Y, et al.; the ABSORB China Investigators. Comparison of everolimus-eluting bioresorbable vascular scaffolds and metallic stents: three-year clinical outcomes from the ABSORB China randomised trial. Eurointervention 2017 in press. doi: 10.4244/EIJ-D-17-00796. 